\title{
Geometric Correction Analysis of Highly Distortion of Near Equatorial Satellite Images Using Remote Sensing and Digital Image Processing Techniques
}

\author{
Hayder Dibs ${ }^{1}\left(\mathbb{D}\right.$, Shattri Mansor $^{2}$, Noordin Ahmad ${ }^{3}$, Nadhir Al-Ansari ${ }^{*}$ \\ ${ }^{1}$ Water Resources Management Engineering Department, Faculty of Water Resources Engineering, Al-Qasim Green University, \\ Babylon, Iraq \\ ${ }^{2}$ Faculty of Engineering, Geospatial Information Science Research Centre, Department of Civil Engineering, University Putra \\ Malaysia, Selangor, Malaysia \\ ${ }^{3}$ National Space Agency Malaysia (ANGKASA), Kementerian Sains, Teknologi dan Inovasi, Pusat Angkasa Negara, \\ Selangor, Malaysia \\ ${ }^{4}$ Department of Civil Environmental and Natural Resources Engineering, Lulea University of Technology, Lulea, Sweden \\ Email: Dr.hayderdibs@wrec.uoqasim.edu.iq, shattri@upm.edu.my,noordin.ahmad@gmail.com, *nadhir.alansari@ltu.se
}

How to cite this paper: Dibs, H., Mansor, S., Ahmad, N. and Al-Ansari, N. (2022) Geometric Correction Analysis of Highly Distortion of Near Equatorial Satellite Images Using Remote Sensing and Digital Image Processing Techniques. Engineering, 14, 1-8.

https://doi.org/10.4236/eng.2022.141001

Received: December 9, 2021

Accepted: January 4, 2022

Published: January 7, 2022

Copyright (c) 2022 by author(s) and Scientific Research Publishing Inc. This work is licensed under the Creative Commons Attribution International License (CC BY 4.0).

http://creativecommons.org/licenses/by/4.0/

\section{(c) (i) Open Access}

\begin{abstract}
The Near-equatorial orbit (NEqO) satellite represents a new generation of optical satellite images characterized by nonlinear distortion when captured. Conventional modeling techniques are insufficient to overcome the geometric distortion in these satellite images. This study proposes a new methodology for overcoming the geometric distortion of the NEqO images. The data used are obtained from RazakSAT and SPOT-5 satellite images in Malaysia. The method starts with applying the RI-SIFT algorithm to extract control points (CPs) automatically. These $\mathrm{CPs}$ are used to solve for the transformation parameters of the geometric correction model by applying spline transformations. The result is verified through statistical comparison: 1) geometric correction on the RazakSAT image is performed with Spot satellite image with using first-order polynomial trans-formation. 2) Then calculate the root mean square error (RMSE). 3) Compare the calculated RMSE with that obtained from the first step with that of the proposed method. The RMSE value of the geometric corrections using the proposed method was $7.08 \times 10^{-9} \mathrm{~m}$. The proposed method provides promising results.
\end{abstract}

\section{Keywords}

Near Equatorial Satellite, Geometric Correction, Automatic Extraction of CPs, RI-SIFT, Sum of Absolute Difference 


\section{Introduction}

The geometric processing of remote-sensing images is a key issue in multiple-source data integration, management, and analysis in many geometric applications [1]. The NEqO satellite images significantly differ in viewing points, solar zenith and azimuth angles, satellite zenith and azimuth angles, capture times, illumination, altitude, and satellite attitudes during imaging [1] [2] [3]. These differences cause the captured images to exhibit highly nonlinear distortion and result in the absence of geometric matching between similar features from two NEqO images even if the images are obtained from the same strip. As a result, the images become unusable and cannot be processed by using conventional geometric correction algorithms; the congenital geometric model cannot overcome the highly non-linear distortion of this kind of images such as the first polynomial transformation [1]. The algorithms for geometric correction can be broadly classified into three: systematic correction, non-systematic correction, and a combination of the two [4]-[9]. The RazakSAT revisits the same area in Malaysia and other countries along the equator 14 times per day. The aim of this study is to apply a new model not applied before to overcome with the nonlinear distortion of $\mathrm{NEqO}$ satellite images of Razaksat satellite by applying this new technique.

\section{Materials and Methods}

\section{Description of the Study Area}

The study area is located south of Pahang State, Malaysia. It includes several districts and lies between $102^{\circ} 18^{\prime} 10.52^{\prime \prime} \mathrm{E}-103^{\circ} 27^{\prime} 49.36^{\prime \prime} \mathrm{E}$ and $02^{\circ} 38^{\prime} 11.12^{\prime \prime} \mathrm{N}$ $02^{\circ} 52^{\prime} 23.34^{\prime \prime} \mathrm{N}$. The study area was the result of the overlapping areas of the RazakSAT image and SPOT-5 image, as shown in Figure 1 shows the corner coordinates of the RazakSAT and SPOT-5 images. RazakSAT is a new generation optical NEqO satellite launched to an altitude of $685 \mathrm{~km}$ in space. The coverage

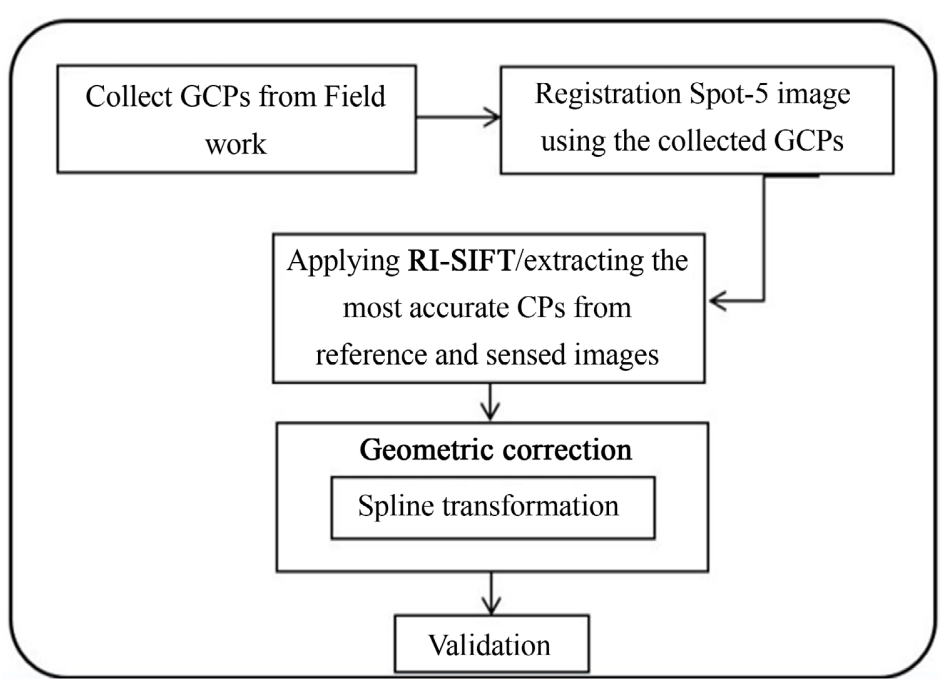

Figure 1. Flowchart of the geometric correction model. 
area size of a RazakSAT image is $20 \mathrm{~km} \times 100 \mathrm{~km}$. RazakSAT has four multispectral bands, namely, red (R), green (G), blue (B), and near infrared (NIR), and one panchromatic band [10]. The spatial resolutions of the multispectral and panchromatic bands are $5 \mathrm{~m}$ and $2.5 \mathrm{~m}$, respectively [10]. The radiometric resolution of a RazakSAT satellite image is 8 bit. The corner coordinates were obtained from the header file of the RazakSAT image. The image was acquired on August 1, 2009. In this study, the RazakSAT image was considered as the sensed image on which the geometric correction model was implemented. The second satellite image used in this study was the SPOT-5 satellite image, which was considered as the reference image.

Figure 2 describes the methodology of this study.

A geometric correction model for $\mathrm{NEqO}$ satellite imagery was implemented in the present study by applying a new approach called refine-and-improve scaleinvariant feature transform (RI-SIFT) as reported in [10] [11] [12]. The proposed geometric correction model for $\mathrm{NEqO}$ imagery was implemented through the following four steps:

1) Ground control points (GCPs) were collected from the study area through fieldwork. GCPS were used for the reference image registration.

2) The RI-SIFT method was applied to automatically extract the most accurate CPs from the reference and sensed images. The RI-SIFT method is described in the following paragraphs [13].

The Paken City, Malysia

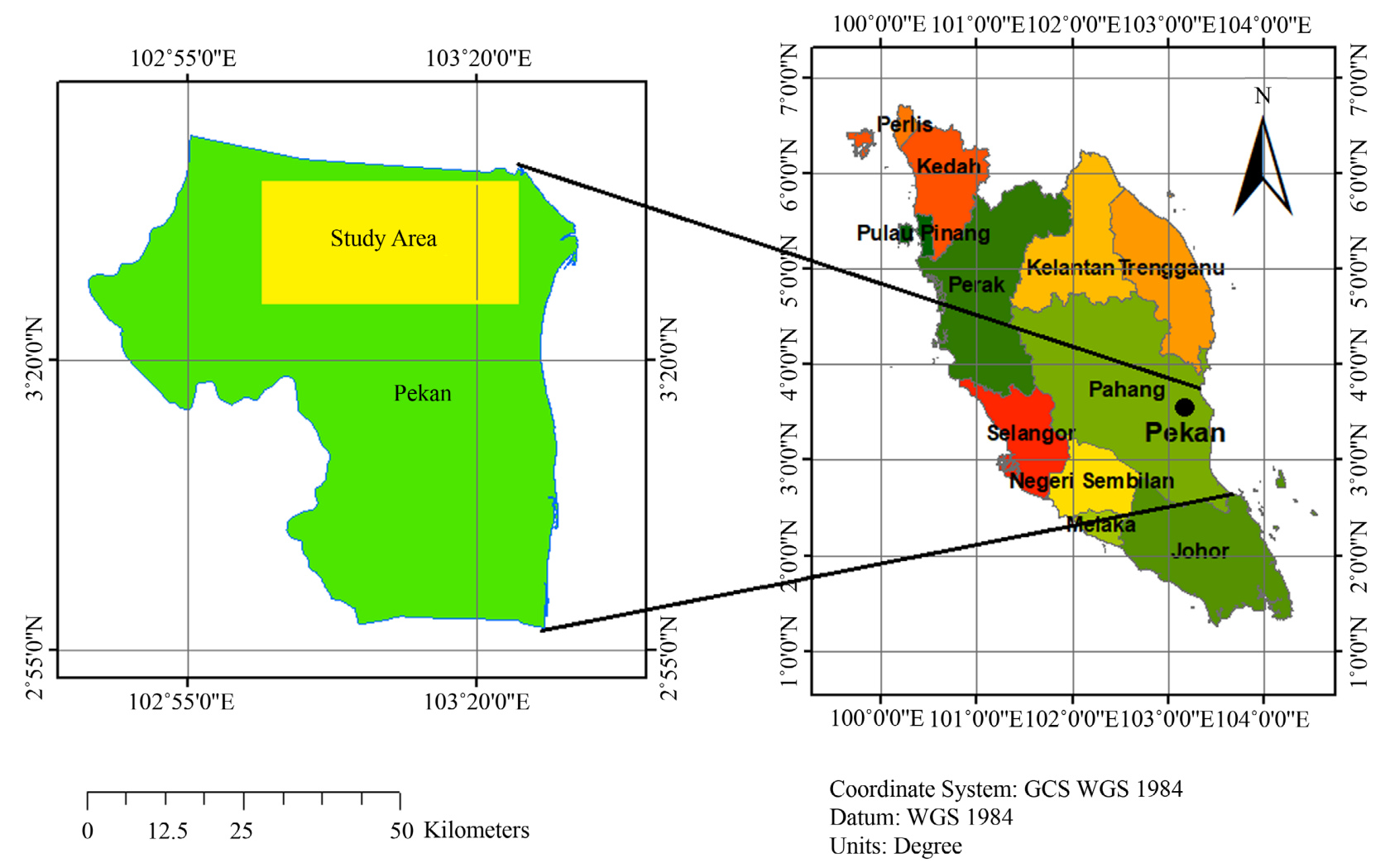

Figure 2. Study area location. 
3) The RI-SIFT method was used to extract, refine, and improve CPs automatically generated from remotely sensed images. RI-SIFT started with data reduction, in which the sensed and reference images were converted into gray-scale images.

4) After the extracted SIFT CPs were automatically refined, these CPs were used in the spatial interpolation to calculate the transformation coefficients. Spline transformation was performed to conduct the spatial interpolation between the SPOT-5 and RazakSAT images.

5) The geometric correction of $\mathrm{NEqO}$ images was verified through the following steps: first, the RazakSAT image was registered directly to the SPOT-5 image using first-order polynomial transformation. Second, the root-mean-square error (RMSE) of the first step was compared with the RMSE of the proposed method to determine the accuracy of the proposed method with regard to geometric correction by first-order polynomial transformation.

6) The Matlab, Arc Map version 10.3 were used for conducting this research.

The acquisition dates for the SPOT-5 images were 12/05/2012, 27/05/2012, 09/03/2013, 10/06/2013, 10/06/2013, and 28/07/2013. Fieldwork was performed on September 5-9, 2014. Digital global positioning System used for collecting 21 different locations to collect 49 GCPs. Table 1 shows the used instrument for fieldwork and Figure 3 presents several fieldwork photographs.

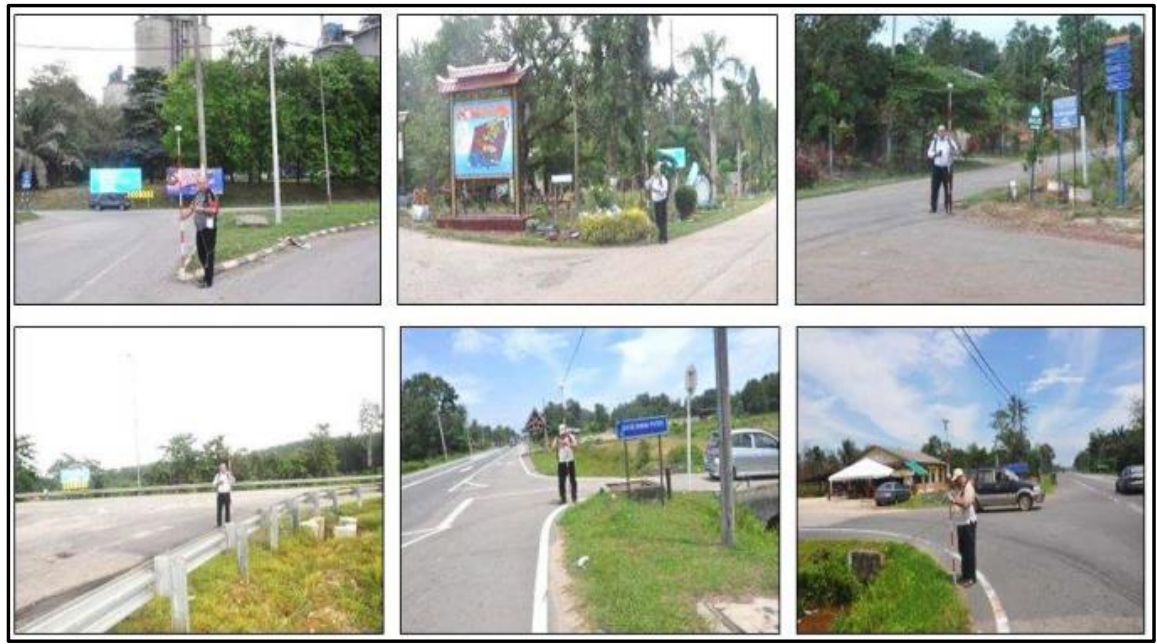

Figure 3. Fieldwork in Malaysia.

Table 1. Fieldwork equipment.

\begin{tabular}{ccc}
\hline Items & Instrument & Type \\
\hline 1 & Digital global positioning system (DGPS) & hemisphere MD A30 \\
2 & Handheld Garmin GPS & etrex 30 \\
3 & Digital camera & Nikon D5000 \\
4 & Pole & total Elev. $=2.44 \mathrm{~m}$ \\
\hline
\end{tabular}


At this stage, the SPOT-5 image was registered using the collected GCPs from field-work. Thereafter, the overlapping area between the SPOT-5 and RazakSAT images was identified. The geometric correction for the RazakSAT images was performed on this particular area. The total RMSE of the registered SPOT-5 image was $5.75 \times 10^{-10} \mathrm{~m}$.

\section{Results and Discussion}

A sharpen high-pass filter was selected to filter the SPOT-5 and RazakSAT images to extract the CPs more easily and more effectively [13] [14]. The next step is applying RI-SIFT to automatically generate the CPs from the reference and sensed images (SPOT-5 and RazakSAT images) under the MATLAB environment. The produced CPs should be invariant to rotation, skewness, scale, and illumination [15] [16]. This step is considered as the most important, because it allows for the identification of the most accurate CPs from the extracted CPs and removal of false CPs and incorrect matches generated from running the SIFT algorithm. Table 2 shows the most accurate extracted CPs of applied RI-SIFT.

\section{Spline Function for Geometric Transformation}

All 14 CP pairs extracted by RI-SIFT were used in the geometric correction of the RazakSAT image by employing the spline transformation function. Applying spline transformation yielded precise and accurate results [17] [18]. After performing spatial transformation by spline transformation, the RMSE was $1.42 \times$ $10^{-10}$ pixels, which was equivalent to $7.08 \times 10^{-9} \mathrm{~m}$. Figure 4 shows the final registered RazakSAT image using the RI-SIFT CPs and the spline approach.

The validation of this study starts with the registration of the RazakSAT image directly to the SPOT-5 image using first-order polynomial transformation, then compared with the RMSE of the proposed method. It was a high distortion in the RazakSAT image after applying first-order polynomial transformation. Table 3 presents the RMSE results of both methods. This result shows the weakness of directly applying first-order polynomial transformation in performing geometric distortions in NEqO images and the high accuracy result of the proposed method.

Table 2. The most accurate CPs by RI-SIFT.

\begin{tabular}{cccccccccc}
\hline Pts. & $\mathrm{Y} 1$ & $\mathrm{X} 1$ & $\mathrm{Y} 2$ & $\mathrm{X} 2$ & Pts. & $\mathrm{Y} 1$ & $\mathrm{X} 1$ & $\mathrm{Y} 2$ & $\mathrm{X} 2$ \\
\hline 1 & 2725.0 & 5570.7 & 2731.2 & 6002.7 & 8 & 3256.5 & 4968.4 & 3345.1 & 5420.7 \\
2 & 2810.2 & 5487.1 & 2833.2 & 5918.2 & 9 & 3001.3 & 5492.6 & 3014.4 & 5934.6 \\
3 & 0514.7 & 3344.0 & 0960.5 & 3678.6 & 10 & 2685.4 & 6544.4 & 2543.8 & 6974.1 \\
4 & 2826.5 & 5419.9 & 2860.8 & 5847.1 & 11 & 2685.4 & 6544.4 & 2543.8 & 6974.1 \\
5 & 3072.1 & 5675.4 & 3054.9 & 6126.5 & 12 & 2648.1 & 6311.7 & 2542.2 & 6742.4 \\
6 & 2829.3 & 5306.6 & 2877.9 & 5742.5 & 13 & 329.8 & 4370.6 & 619.6 & 4698.1 \\
7 & 3256.5 & 4968.4 & 3345.1 & 5420.7 & 14 & 2872.2 & 5175.4 & 2941.3 & 5607.4 \\
\hline
\end{tabular}




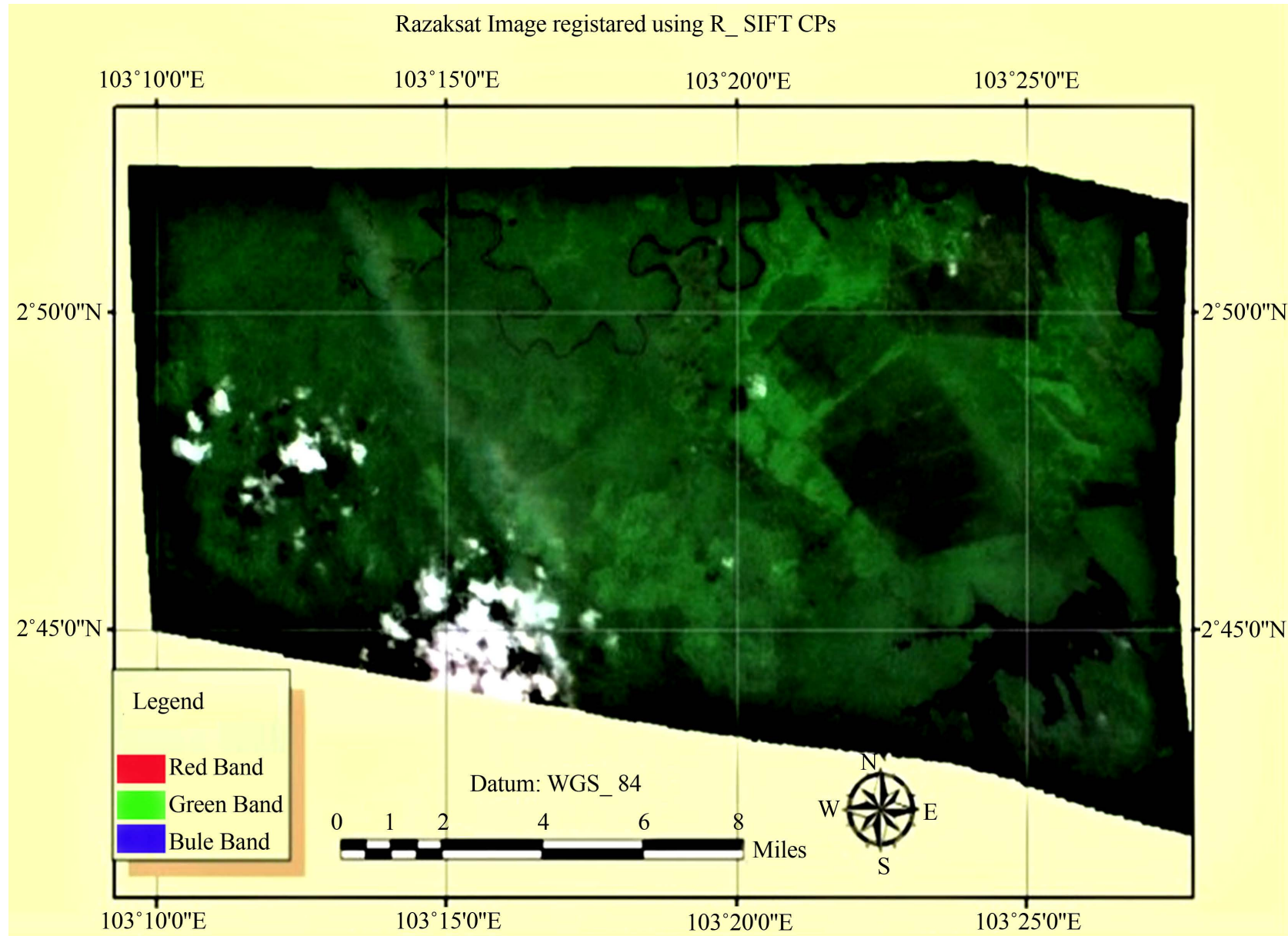

Figure 4. Registered RazakSAT image using RI-SIFT CPs and the spline approach.

Table 3. Comparison of the first-order polynomial versus spline and RI-SIFT.

\begin{tabular}{ccc}
\hline Registration algorithm & RMSE (Pixel) & RMSE (meter) \\
\hline Spline and RI-SIFT & $1.42 \times 10^{-10}$ & $7.08 \times 10^{-9}$ \\
$1^{\text {st }}$ order polynomial & 20.80 & 104 \\
\hline
\end{tabular}

Using conventional techniques to overcome nonlinear geometric distortion of $\mathrm{NEqO}$ images such as polynomial transformation will not able to correct NEqO images geometrically [17] [19] [20]. However, regarding to the outcomes of the prosed method, using the proposed method of extracted CPs from NEqO images automatically by RI-SIFT and spline transformation is able to perform geometric correction of $\mathrm{NEqO}$ images with precise result. Moreover, the processing time and storage size will reduce dramatically. The geometric processing of remote sensing images is a key issue in multi-source data integration, management, and analysis in many geometric applications.

\section{Conclusion}

Geometric correction is a major challenge in different kinds of remote sensing 
applications, especially for $\mathrm{NEqO}$ satellite images, simply because, these images suffer from nonlinear distortion. The RazakSAT is a NEqO satellite images suffering from this kind of distortion because of their differences in illuminations, solar zenith and azimuth angles, altitudes, satellite zenith and azimuth angles, viewing points, and platform attitudes (roll, pitch, and yaw) during image capture. So, there is not any approach that can overcome with this nonlinear distortion and these images become useful to adopt for any application. So, the proposed method adopts a new method dealing with feature extraction to extract the corrected CPs in order to use in the solve function transformation. The proposed approach provides a result that reaches the subpixel accuracy level of 1.42 $\times 10^{-10}$. The results of the comparative evaluation reflect how reliable and flexible the proposed approach is in overcoming the nonlinear distortion in a $\mathrm{NEqO}$ image. The authors of this study believe that the proposed geometric correction model can be applied to mosaicking and can be used to correct multi-sensor images.

\section{Conflicts of Interest}

The authors declare no conflicts of interest regarding the publication of this paper.

\section{References}

[1] Mazlan, H.M., Mahallawy, M.N., Aisya, A.A., Samsudin, A., Xen, Q.Y., Maged, M. and Ahmad S.A. (2013) Geometric and radiometric evaluation of Razaksat Medium-Sized Aperture Camera Data. International Journal of Remote Sensing, 34, 3947-3967. https://doi.org/10.1080/01431161.2013.770581

[2] Toutin, T. (2004) Geometric Processing of Remote Sensing Images: Models, Algorithms and Methods. International Journal of Remote Sensing, 25, 1893-1924. https://doi.org/10.1080/0143116031000101611

[3] Wolnicwicz, W. (2004) Assessment of Geometric Accuracy of VHR Satellite Images. International Archives of Photogrammetry and Remote Sensing and Spatial Information Sciences, 34, 19-23.

[4] Schowengerdt, R.A. (1997) Remote Sensing, Models and Methods, for Image Processing. 2nd Edition, Academic Press, Cambridge.

[5] Montenbruck, O. and Gill, E. (2001) Satellite Orbits: Models, Methods and Applications. Springer, Berlin, Heidelberg. https://doi.org/10.1007/978-3-642-58351-3

[6] Rees, W.G. (2001) Physical Principles of Remote Sensing, 2nd Edition, Cambridge University Press, Cambridge. https://doi.org/10.1017/CBO9780511812903

[7] Lillesand, T.M. and Kiefer, R.W. (2003) Remote Sensing and Image Interpretation. 4rth Edition, John Wiley and Sons Inc., Singapore.

[8] Toutin, T. (2003) Error Tracking in IKONOS Geometric Processing Using a 3D Parametric Modeling. Photogrammetric Engineering and Remote Sensing, 69, 43-51. https://doi.org/10.14358/PERS.69.1.43

[9] Wu, A.M., Lee, Y.Y., Kuo, P. and Kao, R. (2003) ROCSAT-2 Imaging Planning and Scheduling. Presented at the 1 st Taipei International Conference on Digital Earth, Taipei, 1-9.

[10] Hayder, D., Shattri, M., Noordin, A. and Biswajeet, P. (2015) Band-to-Band Regis- 
tration Model for Near-Equatorial Earth Observation Satellite Images with the Use of Automatic Control Points Extraction. International Journal of Remote Sensing, 36, 2184-2200. https://doi.org/10.1080/01431161.2015.1034891

[11] Hayder, D., Shattri, M., Noordin, A., Biswajeet, P. and Nadhir, A., (2020) Automatic Fast and Robust Technique to Refine Extracted SIFT Key Points for Remote Sensing Images. Journal of Civil Engineering and Architecture, 14, 339-350.

https://doi.org/10.17265/1934-7359/2020.06.005

[12] Hayder, D., Hashim, A.H., Jawad, K.A. and Nadhir, A. (2020) An Optimal Approach for Land-Use/Land-Cover Mapping by Integration and Fusion of Multispectral Landsat OLI Images: Case Study in Baghdad, Iraq. Water, Air, \& Soil Pollution, 231, Article No. 488. https://doi.org/10.1007/s11270-020-04846-x

[13] Lowe, D.G. (1999) Object Recognition from Local Scale-Invariant Features. Proceedings of the 7 th IEEE International Conference on Computer Vision, Kerkyra, 20-27 September 1999, 1150-1157. https://doi.org/10.1109/ICCV.1999.790410

[14] Lowe, D.G. (2004) Distinctive Image Features from Scale-Invariant Key-Points. International Journal of Computer Vision, 60, 91-110.

https://doi.org/10.1023/B:VISI.0000029664.99615.94

[15] Gonzalez, R.C. and Woods, R.E. (2008) Digital Image Processing. 3rd Edition, Pearson Prentice Hall, Hoboken.

[16] Wong, A. and Clausi, D.A. (2010) AISIR: Automated Inter-Sensor/Inter-Band Satellite Image Registration Using Robust Complex Wavelet Feature Representations. Pattern Recognition Letters, 31, 1160-1167. https://doi.org/10.1016/j.patrec.2009.05.016

[17] Qian, D., Nareenart, R., Aksuntorn, A.O. and Lori, M.B. (2008) Automatic Registration and Mosaicking for Airborne Multispectral Image Sequences. Photogrammetric Engineering \& Remote Sensing, No. 2, 169-181. https://doi.org/10.14358/PERS.74.2.169

[18] Nielsen, A.A. (2011) Kernel Maximum Autocorrelation Factor and Minimum Noise Fraction Transformations. IEEE Transactions on Image Processing, 20, 612-624. https://doi.org/10.1109/TIP.2010.2076296

[19] Afify, H., Helmy, A. and El, S. (2013) Relative Radiometric Normalization techniques of QuickBird Images, Case Study: Alexandria City. Time Journals of Engineering and Physica, 1, 19-27.

[20] Chen, J., Jiang, T., Lu, W. and Han, M. (2010) The Geometric Correction and Accuracy Assessment Based on Cartosat-1 Satellite Image. The 3rd International Congress on Image and Signal Processing (CISP 2010), Yantai, 16-18 October 2010, 1253-1257. https://doi.org/10.1109/CISP.2010.5647273 